Supporting Information

\title{
A periplasmic binding protein for pyrroloquinoline quinone
}

\author{
Jackson V. Ho and Joseph A. Cotruvo, Jr.* \\ Department of Chemistry, The Pennsylvania State University, University Park, PA 16802 \\ * Corresponding author. E-mail: juc96@psu.edu (J.A.C.) \\ This file contains Experimental Procedures, Supplementary Tables S1 and S2, Supplementary \\ Figures S1-S15, and Supplementary References.
}

\section{EXPERIMENTAL PROCEDURES}

General considerations

Cloning of MexAM1_META1p1737 (PqqT) and variants

Expression and purification of His 6 -tagged, full-length PqqT

Expression and purification of His6-tagged, cytosolic PqqT

Expression and purification of His6-tagged, cytosolic PqqT-C192A

Mass spectrometry of PqqT constructs

DTNB assays

Spectrophotometric titrations

Spectrofluorometric titrations

Anaerobic titrations

Isothermal titration calorimetry

\section{SUPPLEMENTARY TABLES}

Table S1. Plasmids used in this study

Table S2. Primers used in this study

\section{SUPPLEMENTARY FIGURES}

Figure S1. Genomic context of MexAM1_META1p1737 (pqqT)

Figure S2. Amino acid sequence of MexAM1_META1p1737 and codon-optimized gBlock

Figure S3. Sequence alignment with predicted PqqT homologues

Figure S4. Homology model of PqqT

Figure S5. Expression and purification of full-length PqqT-His

Figure S6. SDS-PAGE analysis of purifications of cytosolic PqqT and PqqT-C192A; mass spectrometry analysis of cytosolic PqqT

Figure S7. Mass spectrometry analysis of tryptic digests of cytosolic and periplasmic PqqTs

Figure S8. Mass spectrometry evidence for desulfuration of Cys 192 
Figure S9. Characterization of exported PqqT-His, purified from the E. coli periplasm Figure S10. UV-visible absorption spectra of PQQ and PQQ-hydrate

Figure S11. Titration of PQQ with PqqT monitored by UV-visible spectrophotometry Figure S12. Comparison of the spectra of PQQ and PQQ bound to PqqT-C192A

Figure S13. Spectrophotometric and fluorometric titrations of PqqT-C192A

Figure S14. PQQ binding to PqqT-C192A, studied by isothermal titration calorimetry Figure S15. ITC titration of PqqT-C192A with folate

\section{SUPPLEMENTARY REFERENCES}




\section{EXPERIMENTAL PROCEDURES}

General considerations. Chemical reagents were obtained from Sigma-Aldrich or Fisher at the highest purity available. Primers were ordered from Integrated DNA Technologies (IDT). E. coli strains [5alpha and BL21(DE3)] for cloning and recombinant protein expression, as well as cloning reagents (restriction enzymes, Q5 DNA polymerase, OneTaq DNA polymerase, and T4 DNA ligase) were obtained from New England Biolabs. PCR cleanup and miniprep kits were from Omega Bio-tek, and gel extractions used the Zymoclean gel DNA recovery kit from Zymo Research. Ni-NTA resin was purchased from Thermo Scientific. Protein gel electrophoresis was carried out using Life Tech 16\% Tris-glycine gels and a mini gel apparatus. Automated protein chromatography was carried out on a GE Healthcare Biosciences Akta Pure fast protein liquid chromatography (FPLC) system. UV-visible absorption spectra were obtained on an Agilent Cary $60 \mathrm{UV}$-visible spectrophotometer, and spectrofluorometric titrations were carried out using a Cary Eclipse fluorescence spectrophotometer, using 10-mm pathlength quartz cuvettes (Starna Cells).

Cloning of MexAM1_META1p1737 (PqqT) and variants. The soluble domain of $M$. extorquens, AM1_META1p1737 was obtained as a 1031-bp gBlock gene fragment containing a 5' NdeI restriction site, C-terminal hexahistidine tag, and a 3' EcoRI site, and was codon optimized for expression in E. coli using IDT's online codon optimization tool (Figure S2). The gBlock was digested with NdeI and EcoRI-HF for 1 hour and purified via PCR clean up kit (Omega Bio-tek). pET-24a $(2 \mu \mathrm{g})$ was digested with NdeI and EcoRI-HF, and following gel electrophoresis (1\% agarose), the vector fragment was excised and purified using the Zymoclean Gel DNA Recovery Kit. The insert was ligated into the digested vector (3:1 insert:vector) using T4 DNA ligase according to the manufacturer's protocol, yielding pET24a-PqqT-His (Table S1). For construction of PqqT-His lacking the N-terminal signal peptide, primers PqqT-cyto-for and PqqT-cyto-rev (Table S2) were used to amplify the protein starting from Ala28, followed by an analogous digestion and ligation procedure, yielding pET24a-cyto-PqqT-His. For mutagenesis of Cys192 to Ala, a KLD reaction was performed according to the manufacturer's protocol using pET24a-cytoPqqT-His as template and primers C192A-for and C192A-rev (Table S2). In all cases, transformants were screened for insert by colony PCR (OneTaq Quick-Load) and the correct inserts were confirmed by DNA sequencing by Genewiz.

Expression and purification of His6-tagged, full-length PqqT. PqqT-His was expressed from E. coli BL21(DE3) cells transformed with pET24a-PqqT-His and purified from the E. coli periplasm by a procedure as described for LanM-His, ${ }^{1}$ with the following modifications. The expression was carried out on 2-L scale, and at an $\mathrm{OD}_{600 \mathrm{~nm}}=0.5$, the shaker temperature was reduced to $18{ }^{\circ} \mathrm{C}$, and protein expression was induced using $200 \mu \mathrm{M}$ isopropyl $\beta$-D-1thiogalactopyranoside (IPTG, Amresco/VWR) for $9 \mathrm{~h}$. The culture yielded $5 \mathrm{~g}$ cell paste per $\mathrm{L}$ culture. Buffers used for periplasmic extraction and purification contained $5 \mathrm{mM} \beta$ mercaptoethanol, and a $2.5 \times 10 \mathrm{~cm}(10 \mathrm{~mL}) \mathrm{Ni}$-NTA column was used. The purification yielded $2 \mathrm{mg}$ PqqT per L culture. The protein was analyzed by mass spectrometry on an Ultraflextreme mass spectrometer (Bruker Daltonics) at the Penn State Proteomics and Mass Spectrometry Facility.

Expression and purification of His6-tagged, cytosolic PqqT. Chemically competent E.coli BL21 (DE3) cells were transformed with pET24a-cyto-PqqT-His and plated on LB-agar plates 
containing $50 \mu \mathrm{g} / \mathrm{mL}$ kanamycin $(\mathrm{Km})$ and growth at $37^{\circ} \mathrm{C}$. A single colony was used to inoculate $100 \mathrm{~mL}$ of LB $\left(50 \mu \mathrm{g} / \mathrm{mL} \mathrm{Km}\right.$ in all growth media), grown for $\sim 16 \mathrm{~h}$ at $37^{\circ} \mathrm{C}$ with shaking at 200 $\mathrm{rpm}$. Twenty $\mathrm{mL}$ of the overnight culture were used to inoculate $3 \times 2 \mathrm{~L}$ culture (in a 6 - $\mathrm{L}$ flask) of LB media supplemented with $0.5 \mathrm{mM} \mathrm{MgCl}_{2}$ and $0.5 \mathrm{mM} \mathrm{CaCl}_{2}$, and the culture were grown at $37{ }^{\circ} \mathrm{C}$ with shaking at $200 \mathrm{rpm}$. At $\mathrm{OD}_{600 \mathrm{~nm}} \sim 0.5$, the flasks were cooled in the $4{ }^{\circ} \mathrm{C}$ cold room and the shaker was turned to $18^{\circ} \mathrm{C}$. IPTG was added to a final concentration of $200 \mu \mathrm{M}$ and incubated overnight at $18{ }^{\circ} \mathrm{C}$, the cells were pelleted by centrifugation for $7 \mathrm{~min}$ at $7000 \times g, 4{ }^{\circ} \mathrm{C}$, yielding $4.7 \mathrm{~g}$ cell paste per L culture.

The cell paste was re-suspended in $5 \mathrm{~mL} / \mathrm{g}$ of $50 \mathrm{mM}$ sodium phosphate, $10 \mathrm{mM}$ imidazole, $5 \%$ glycerol, $5 \mathrm{mM} \beta$-mercaptoethanol, $\mathrm{pH} 7.0$ (Buffer A), four protease inhibitor cocktail tablets (cOmplete Tablets, Mini EDTA-Free), and $300 \mathrm{U}$ of DNase. The suspension was sonicated with a $1 / 4$ " (6 mm) microtip at 50\% amplitude, with cycles of $20 \mathrm{~s}$ pulse on / $40 \mathrm{~s}$ pulse off for $20 \mathrm{~min}$ (QSonica). After sonication, the suspension was centrifuged at $37,000 \times g$ for $30 \mathrm{~min}$. The supernatant was applied to a $2.5 \times 10 \mathrm{~cm}(10 \mathrm{~mL})$ Ni-NTA column, pre-equilibrated in $50 \mathrm{~mL}$ Buffer A. The column was washed with 15 column volumes (CV) of Buffer A containing $100 \mathrm{mM}$ $\mathrm{NaCl}$ and $0.25 \mathrm{mM}$ PMSF (Buffer B) followed by a $5 \mathrm{CV}$ of Buffer A. The protein was eluted using $5 \mathrm{CV}$ of $50 \mathrm{mM}$ sodium phosphate, $250 \mathrm{mM}$ imidazole, $5 \mathrm{mM} \beta$-mercaptoethanol, $5 \%$ glycerol, pH 7.0 (Buffer $\mathbf{C}$ ). The protein was concentrated to $<5 \mathrm{~mL}$ using an Amicon Ultra 15 10-kDa MWCO centrifugal filter.

Higher molecular weight contaminants were removed and buffer exchanged into $30 \mathrm{mM}$ MOPS, $100 \mathrm{mM} \mathrm{KCl}$, pH 7.0 (Buffer D), containing $5 \mathrm{mM} \beta$-mercaptoethanol, by size-exclusion chromatography on a HiLoad 16/600 Superdex 75 pg column (GE Healthcare). The protein sample was loaded using a $5 \mathrm{~mL}$ capillary loop and eluted using $1.2 \mathrm{CV}$ of Buffer D, with 1-mL fractions collected (1 mAU threshold in peak fractionation). PqqT eluted at 59-79 mL (peak at $68.2 \mathrm{~mL}$ corresponds to an apparent molecular weight of $26 \mathrm{kDa}$ ). PqqT concentration was determined using $\varepsilon_{280 \mathrm{~nm}}=32430 \mathrm{M}^{-1} \mathrm{~cm}^{-1}{ }^{2}$ The purification yielded $63 \mathrm{mg}$ PqqT per L culture.

Expression and purification of PqqT-C192A. His-tagged, cytosolic PqqT-C192A was expressed and purified by an analogous protocol to the wildtype protein lacking the signal peptide, except that the purification buffers did not include reductant. PqqT-C192A eluted from the Superdex 75 column at 59-72 $\mathrm{mL}$ (peak at $64.8 \mathrm{~mL}$ corresponds to an apparent molecular weight of $33 \mathrm{kDa}$ ), yielding $\sim 106 \mathrm{mg}$ per L culture.

\section{Mass spectrometry of PqqT constructs.}

a) MALDI-TOF mass spectrometry. Mass spectra of PqqT were acquired on a Bruker Ultraflextreme MALDI TOF-TOF instrument using a factory-configured instrument method for linear positive-ion detection over the $5,000-50,000 \mathrm{~m} / \mathrm{z}$ range. The matrix was prepared by combining 1 volume of $18 \mathrm{mg} / \mathrm{mL}$ aqueous solution of ammonium dihydrogen citrate and 3 volumes of a $20 \mathrm{mg} / \mathrm{mL} \mathrm{2,6-dihydroxyacetophenone} \mathrm{solution} \mathrm{in} \mathrm{ethanol.} \mathrm{Protein} \mathrm{samples} \mathrm{and}$ standards were mixed with the matrix and a $2 \%$ trifluoroacetic acid solution in 1:1:1 volumetric ratio, and $1 \mu \mathrm{L}$ of this mixture was applied to a polished steel target. Laser power attenuation and pulsed ion extraction time were optimized to achieve the best signal. Instrument was calibrated using a mixture of 5 protein standards: bovine insulin, bovine ubiquitin, equine heart cytochrome $c$, chicken egg lysozyme, and equine apomyoglobin. Mass spectra were smoothed (SavitzkyGolay, width $5 \mathrm{~m} / \mathrm{z}, 1$ cycle) and baseline subtracted (TopHat). Mass lists were generated using a centroid peak detection algorithm. 
The tryptic peptides of C-terminally $\mathrm{His}_{6}$-tagged PqqT, purified from the cytosol and periplasm, were analyzed using the reflector positive-ion detection over the $500-5000 \mathrm{~m} / \mathrm{z}$ range. Laser power attenuation and pulsed ion extraction time were optimized to achieve the best signalto-noise. The instrument was calibrated with a Proteomass MALDI Peptide Calibration Mix High Range (SigmaMSCAL4-1KT). Mass spectra were processed in FlexAnalysis. Spectra were smoothed (SavitzkyGolay, $0.2 \mathrm{~m} / \mathrm{z}, 1$ cycle), baseline-subtracted (TopHat), and the mass lists were generated using a Snap peak detection algorithm with signal-to-noise threshold set at 6 and using the Averagine SNAP average composition.

b) Proteolysis. Reduction and alkylation of the protein Cys residues were carried out in 5 $\mathrm{mM}$ tris(2-carboxyethyl)phosphine hydrochloride and $5 \mathrm{mM}$ iodoacetamide solutions in $50 \mathrm{mM}$ aqueous triethylammonium bicarbonate for $20 \mathrm{~min}$ at room temperature, after which the excess reagents were removed using centrifugal filters with $3 \mathrm{kDa}$ membranes. A $1 \mu \mathrm{g} / \mu \mathrm{L}$ stock solution of sequencing-grade trypsin (Thermo) in $50 \mathrm{mM}$ aqueous acetic acid was diluted 10-fold with chilled $200 \mathrm{mM}$ aqueous triethylammonium bicarbonate, and $30 \mu \mathrm{L}$ of this solution was added to $20 \mu \mathrm{L}$ of $3 \mathrm{mg} / \mathrm{mL}$ solutions of C-terminally His $6^{-}$tagged PqqT, purified from the cytosol and periplasm. Proteolysis was carried out for $4 \mathrm{~h}$ at $38^{\circ} \mathrm{C}$. Prior to MS analysis, peptides were cleaned using PepClean spin columns containing $8 \mathrm{mg} \mathrm{C} 18$ resin (Pierce, Thermo).

c) Nano-LC/MS $S^{2}$. The peptides $(2 \mu \mathrm{L})$ were loaded onto an Acclaim PepMap100 trapping column $(100 \mu \mathrm{m} \times 2 \mathrm{~cm}, \mathrm{C} 18,5 \mu \mathrm{m}, 100 \AA$, Thermo $)$ at a flow rate of $20 \mu \mathrm{L} / \mathrm{min}$ using $2 \%$ aqueous acetonitrile, $0.1 \%$ formic acid as the mobile phase. The peptides were separated on an Acclaim PepMap RSLC column $(75 \mu \mathrm{m} \times 15 \mathrm{~cm}, \mathrm{C} 18,2 \mu \mathrm{m}, 100 \AA$, Thermo) with a 30 -min $2 \%-35 \%$ linear gradient of acetonitrile in water containing $0.1 \%$ formic acid. The gradient was delivered by a Dionex Ultimate 3000 nano-LC system (Thermo) at $300 \mathrm{~nL} / \mathrm{min}$. An LTQ Orbitrap Velos mass spectrometer (Thermo) was operated in a ' $2^{\text {nd }}$ order double play' mode with the following datadependent parameters: full FT-MS scan at R 60,000 followed by 10 ion-trap $\mathrm{MS}^{2}$ scans on the most intense precursors with CID activation. Only the precursors with charge states +2 and higher were selected for $\mathrm{MS}^{2}$; monoisotopic precursor selection with non-peptide recognition was enabled, and the isolation window was $2 \mathrm{~m} / \mathrm{z}$.

d) Nano-LC/MS $S^{2}$ data analysis. The mass spectra were processed using PEAKS STUDIO 8.5 (Bioinformatics Solutions Inc.). Protein identities were confirmed by searching the De Novo sequence tags against the Methylobacterium extorquens database (TrEMBL, 41934 sequences) to which the common contaminant sequences were appended. The following search parameters were used: precursor tolerance $10 \mathrm{ppm}$, fragment tolerance $0.8 \mathrm{Da}$ (ion trap), carbamidomethyl (+ $57.021 \mathrm{Da}, \mathrm{C}$ ) was set as a variable modification. PEAKS PTM and Spider tools were used to search for unspecified modifications and mutations.

e) HCD FT MS $S^{2}$ analysis of the LYWQFAAR peptide. To confirm the PEAKS Spider search assignment of Cys to Ala mutation based on the low-resolution $\mathrm{MS}^{2}$ data, the protein digest was analyzed using a high-resolution data-independent acquisition method. The HCD FT MS ${ }^{2}$ scans were triggered by $m / z \quad 527.77$ and $m / z \quad 1034.03 \quad(z=2)$, the LYWQFAAR and LETGELDAALLYWQFAAR peptide precursors. The HCD collision energy was stepped from $35 \%$ to $40 \%$ to $45 \%$, the isolation window was $2 \mathrm{~m} / \mathrm{z}$, and the HCD charge state was 2 . The $\mathrm{m} / \mathrm{z}$ of the two peptides' precursor ions and their fragmentation patterns are consistent with the Cys to Ala mutation at the 192 position.

DTNB assay. The free thiol contents of PqqT purified from either the periplasm or cytosol of $E$. coli was assessed by assay with 5,5'-dithiobis-(2-nitrobenzoic acid) (DTNB). ${ }^{3}$ A standard curve 
was prepared by addition of $30 \mu \mathrm{L}$ of $0,0.25,0.5,0.75,1.0,1.25$, and $1.5 \mathrm{mM}$ L-cysteine hydrochloride in $100 \mathrm{mM}$ sodium phosphate, $\mathrm{pH} 8.0$ (Buffer $\mathbf{E}$ ), to $500 \mu \mathrm{L}$ Buffer $\mathrm{E}$ and $10 \mu \mathrm{L}$ $7.5 \mathrm{mM}$ DTNB. The cytosolic and periplasmic proteins $(\sim 400 \mu \mathrm{M})$ were incubated with $5 \mathrm{mM}$ DTT for $10 \mathrm{~min}$ and buffer exchanged using a Zeba spin column into Buffer E. The eluted proteins $(30 \mu \mathrm{L})$ were immediately mixed with $500 \mu \mathrm{L}$ Buffer E and $10 \mu \mathrm{L} 7.5 \mathrm{mM}$ DTNB solution, and $\mathrm{A}_{412 \mathrm{~nm}}$ was measured. The remainder of the protein solution was used to quantify protein by $\mathrm{A}_{280 \mathrm{~nm}}$. The $\mathrm{A}_{412 \mathrm{~nm}}$ value was used with the standard curve to calculate free thiols/protein.

Spectrophotometric titrations. PQQ binding to wt-PqqT and PqqT-C192A was assessed using a Cary $60 \mathrm{UV}$-visible spectrophotometer. The cuvette contained $600 \mu \mathrm{L} \sim 10 \mu \mathrm{M}$ PQQ in Buffer D. The initial PQQ concentration was determined using $\varepsilon_{322 \mathrm{~nm}}=8963 \mathrm{M}^{-1} \mathrm{~cm}^{-1}{ }^{4}$ Into this solution was titrated wt-PqqT or PqqT-C192A from a $\sim 1 \mathrm{mM}$ solution in $\sim 1 \mu \mathrm{M}$ increments, up to $20 \mu \mathrm{M}$ protein. After each addition, spectra were acquired between 240 and $800 \mathrm{~nm}$. For aerobic titrations with the wt protein, immediately prior to the titration, $\beta$-mercaptoethanol present in the storage buffer was removed by two successive buffer exchanges into Buffer D using a $0.5 \mathrm{~mL}$ Zeba Spin desalting column, 7K MWCO. This step was critical, as reduction of PQQ by trace $\beta$ mercaptoethanol interfered with the assay. In order to calculate the spectrum of PQQ at each point in the titration, a spectrum of apoprotein was scaled to the protein concentration and subtracted from the corresponding overall spectrum. A modified protocol for anaerobic titration experiments is described below.

Spectrofluorometric titrations. Fluorescence experiments were carried out using a Varian Cary Eclipse spectrofluorometer at $23{ }^{\circ} \mathrm{C}$. The excitation wavelength was $375 \mathrm{~nm}$, and emission data were collected at 400-700 nm, with $5 \mathrm{~nm}$ excitation and emission slits, $1 \mathrm{~nm}$ steps, $0.4 \mathrm{~s}$ averaging time, and high PMT setting. All samples were $600 \mu \mathrm{L}$ and were prepared in a semi-micro quartz fluorometer cell with $10 \mathrm{~mm}$ path length (Starna Cells). The cuvette contained $10 \mu \mathrm{M}$ PQQ (concentration measured on UV-visible spectrophotometer prior to start of the titration) in Buffer $\mathrm{D}$, into which wt-PqqT or PqqT-C192A was titrated from a $\sim 1 \mathrm{mM}$ solution in 1-2 $\mu \mathrm{M}$ increments, up to $20 \mu \mathrm{M}$ protein. A control titration of protein into buffer showed no significant fluorescence emission under these conditions. All samples were analyzed following subtraction of a blank spectrum of Buffer B. A modified protocol for anaerobic titration experiments (wt-PqqT) is described below.

Anaerobic titrations. All anaerobic sample preparations were carried out in an MBraun glovebox. Protein, buffer, and cofactor solutions were all deoxygenated on a Schlenk line with 3 cycles of evacuation and refilling with Ar prior to introduction to the glovebox. Reductants were removed from protein solutions by spin column, as described above, immediately prior to deoxygenation. The cuvette containing the PQQ solution was sealed with a septum and screw cap. The titrant solution was placed in a $50 \mu \mathrm{L}$ Hamilton syringe fitted to a repeat dispenser. The syringe was inserted into the cuvette and the apparatus was removed from the glovebox for the titration, which was carried out as described above.

Isothermal titration calorimetry. Binding of PQQ and folate (a kind gift from Prof. Stephen J. Benkovic) to wt PqqT and the C192A variant was analyzed by ITC using a MicroCal Auto-iTC200 instrument. All experiments were performed at $25{ }^{\circ} \mathrm{C}$, in Buffer D (without $\beta$-mercaptoethanol) from the dialysis procedure. All solutions were degassed prior to the experiments. The ITC cell 
contained $\sim 30 \mu \mathrm{M}$ wt-LanM. The titrant syringe contained $350 \mu \mathrm{M}$ PQQ or $350 \mu \mathrm{M}$ folate in the same buffer. (Folate concentrations were determined according to $\varepsilon_{368 \mathrm{~nm}}=9120 \mathrm{M}^{-1} \mathrm{~cm}^{-1}$ by dilution of a $\sim 5 \mathrm{mM}$ stock solution into $0.1 \mathrm{M} \mathrm{NaOH} .{ }^{5}$ ) Titration settings were the following: 1000 $\mathrm{rpm}$ stirring speed, $60 \mathrm{~s}$ initial delay, $5 \mu \mathrm{cal} / \mathrm{s}$ reference power, and $180 \mathrm{~s}$ spacing between each injection. Titrations consisted of a first $0.2 \mu \mathrm{L}$ injection followed by $34 \times 1.1 \mu \mathrm{L}$ injections. Titrations of ligand solutions into the cell containing buffer without protein showed negligible heats of dilution. The resulting data were fitted using MicroCal Origin to one set of sites model, provided by the manufacturer, to obtain the number of sites $(n)$, association constant $(K)$, binding enthalpy $(\Delta H)$, and entropy change $(\Delta S)$, from which the free energy change $(\Delta G)$ was calculated. 


\section{SUPPLEMENTARY TABLES}

Table S1. Plasmids used in this study

\begin{tabular}{lll}
\hline Name & Notes & Source \\
\hline pET24a & $\mathrm{Km}^{\mathrm{R}}$ & Novagen \\
pET24a-PqqT-His & C-terminally His 6 -tagged PqqT (full length) & This work \\
pET24a-cyto-PqqT-His & C-terminally His ${ }_{6}$-tagged PqqT, cytosolic & This work \\
& expression & \\
pET24a-cyto-PqqT(C192A)-His & & This work \\
\hline
\end{tabular}


Table S2. Primers used for cloning and sequencing ${ }^{1}$

\begin{tabular}{ll}
\hline Name & Sequence \\
\hline PqqT-cyto-for & 5'-AATACATATGGCGGGTGAAACGTTCCGTTTGGGT-3' \\
PqqT-cyto-rev & 5'-TATTGAATTCTTAGTGATGATGGTGATGATG \\
& ACCATTGCCAGACGCATC-3' \\
C192A-for & 5'-CTGGCAATTTGCGGCCCGTTTAGAAGCTAAAGGGTTTAAAC-3' \\
C192A-rev & 5'-TACAGAAGCGCCGCGTCC-3' \\
Sequencing primers & \\
T7P & 5'-TAATACGACTCACTATAGGG-3' \\
T7T & 5'-GCTAGTTATTGCTCAGCGG-3' \\
\hline${ }^{1}$ Cys to Ala mutation is bolded
\end{tabular}




\section{SUPPLEMENTARY FIGURES}

Figure S1. Genomic context of MexAM1_META1p1737 (pqqT), present in a gene cluster encoding many of the proteins involved in methylotrophy. Gene names, MexAM1_META1p17xx, are abbreviated as META1p17xx, and operon predictions are made by BioCyc and colored accordingly. ${ }^{6}$ pqqT is suggested to be part of an operon including META1p1738 and META1p1739, encoding the permease and ATP-binding components, respectively, of a putative ABC transporter system. This operon is immediately upstream of the operon encoding the core Ln-dependent methanol dehydrogenase proteins, XoxF, XoxG (c-type cytochrome), and XoxJ (a periplasmic binding protein of unknown function). pqqABCDE are genes required for PQQ biosynthesis, ${ }^{7}$ immediately adjacent to META1p1747 and META1p1746, encoding putative periplasmic proteins. folP, folB, and folK are annotated as encoding enzymes involved in the biosynthesis of tetrahydrofolate: ${ }^{8} 7,8$-dihydropteroate synthase, dihydroneopterin aldolase, and 2amino-4-hydroxy-6-hydroxymethyldihydropteridine pyrophosphokinase, respectively. META1p1736 is annotated as a putative bifunctional transcriptional coactivator/pterin dehydratase.

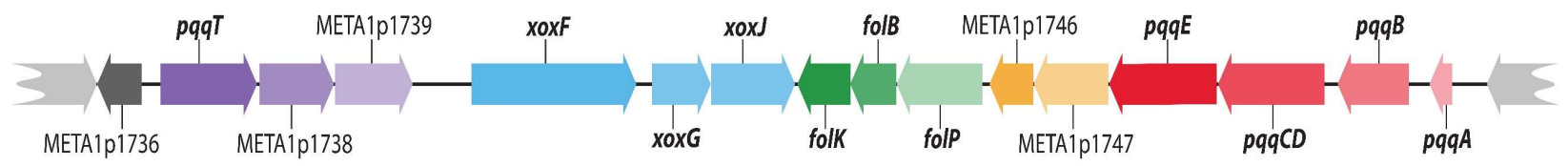


Figure S2. Amino acid sequence of $M$. extorquens AM1 MexAM1_META1p1737 (PqqT) and codon-optimized gBlock for its expression in E. coli. The region encoding the signal peptide (cleaved before Ala28, as confirmed in Figure S5) is shown in red. Restriction sites are underlined and the His 6 tag is shown in blue in the gBlock.

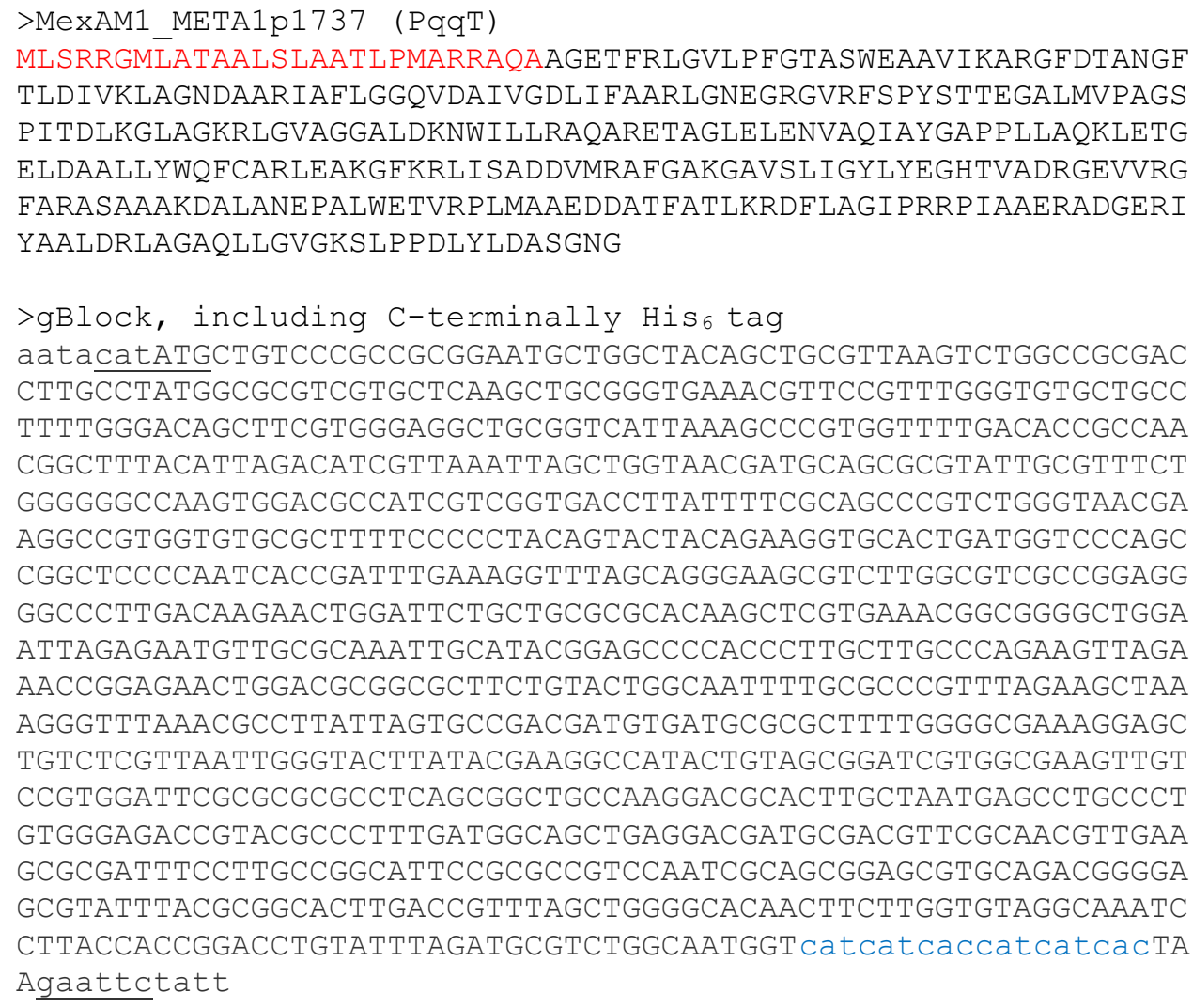


Figure S3. Sequence alignment of PqqT with predicted homologues. Homologues were identified by BLAST search using the full-length PqqT sequence as query. Selected hits were aligned using Clustal Omega. ${ }^{9}$ In addition to the $M$. extorquens AM1 PqqT (META1p1737) sequence below are sequences from the alpha-proteobacteria Methylobacterium aquaticum (WP_060847720.1), Bradyrhizobium elkanii (WP_075968419.1), Rhizobium leguminosarum (WP_129420611.1), and Sinorhizobium meliloti (WP_014530812.1), and the gamma-proteobacteria Methylomonas methanica (WP_013820611.1) and Pseudomonas stutzeri (WP_080940970.1). Identities versus M. extorquens AM1 PqqT are: $62 \%, 40 \%, 39 \%, 39 \%, 41 \%$, and 41\%, respectively. Residues shown in Figure $\mathbf{S} 4$ are in red.

Mex AM1 p1737 WP_ $0608 \overline{4} 7720.1$ WP 075968419.1 WP 129420611.1 WP 014530812.1 WP 013820611.1 WP_-080940970.1

Mex AM1 p1737 WP $0608 \overline{4} 7720.1$ WP 075968419.1 WP 129420611.1 WP 014530812.1 WP 013820611.1 WP_080940970.1

Mex AM1 p1737 WP $0608 \overline{4} 7720.1$ WP 075968419.1 WP_129420611.1 WP 014530812.1 WP_013820611.1 WP 080940970.1

Mex_AM1_p1737 WP $\overline{0} 608 \overline{4} 7720.1$ WP 075968419.1 WP_129420611.1 WP 014530812.1 WP 013820611.1 WP 080940970.1

Mex_AM1_p1737 WP $0608 \overline{4} 7720.1$ WP 075968419.1 WP_129420611.1 WP 014530812.1 WP_013820611.1 WP 080940970.1

Mex_AM1_p1737 WP $\overline{0} 608 \overline{4} 7720.1$ WP 075968419.1 WP_129420611.1 WP 014530812.1 WP_013820611.1 WP 080940970.1

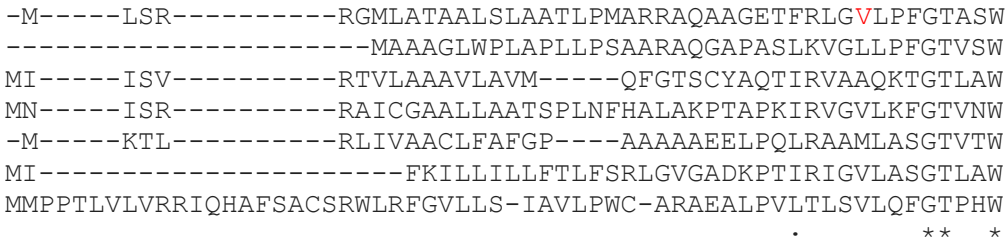

EAAVIKARGFDTANGFTLDIVKLAGNDAARIAFLGGQVDAIVGDLIFAARLGNEGRGVRF EAAVIKAEGIDAAEGLDLEGVRLAGSDAARIAFQGGQVDTIVSDLLWAARLRAEGRAVKF ELAVIRSHGLDKKANLS I DVVELASPEAGKIALRAGTADVMVSDWPWVSRERSLGAKLQF ELDTIKHNQFDAASGIDVEIVYFAGEDATNVAMLAGDLN I IVSDWLWVSRQRSQGADLTI EISTIKTHEFDRKNGFELTVQDYADNGATRVAFEGGEADTMVADWIWVANQRASGKDYVF ELAAIKNANGLDNAGFNLETVAIANQQAGKVALQAGSVDMIVSDWIWVSSMRAQGNDYTF ELEHLKRRQLDHANGFELKVRLAADVPASRLALSSGGVDGAVSDLPWAQTRYEAGSSYRY

* $\quad$ :

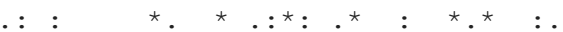

SPYSTTEGALMVPAGSPITDLKGLAGKRLGVAGGALDKNWILLRAQARETAGLELENVAQ LPYSSTEGALMVPGDSSLTTVAGLAGKRLGVAGGPLDKNWLLLRARAREKDGFDLEREAR YPYSSALGAVMVPASSPVKTLADLKGRKLAIAGGA I DKNWLLLQAAS-KQDGVDLKSQAT APYSTAVGAIMVKEDAPIRAI PDLAGKKIGVTGGPLDKSWLLIQGLARRDHKIDLTRESE IPYSRAVGGLMVKDDSGIKALPDLAGKKIGIAGGPLDKSWLI LRAYAROOHDMDLAAETE YPYSASAGGLLVPADSGINSLADLQGKKLGIAGGELDKNWSLLQALG-LQQGLDLNESLE LPFSSQLGEMLVLAGSTIRTLADLRGKRIGVAGGPDGIGWLLLRRAA-AEQGIDLAREAR

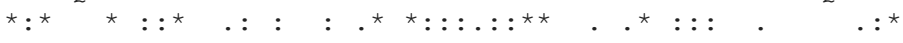

IAYGAPPLLAQKLETGELDAALLYWQFCARLEAKG-FKRLISADDVMRAFGAKGAVSLIG PVFGAPPLLMRKLETGELDAALLYWTFCARLEARG-FRRLIGADGIAAAFGVTGPIALLG IVYGAPPLLAAKTLGGEMDATLNYWNFCAALEAKG-FRRLAGMEEILQKLGSKGRIAMIG VVFGAPPLLSEKAVSGELDAVLNFWHFCARLEVNG-FRRLIGADDAAKALGALGPVSALG QVFGAPPLIFKSALSGETAGT INFWHFLAKMRAKG-MHELVSVSDAAAALKLDPDTPLLG KVYGAPPLLNQQLSSRRIDALLTYWQFAARLEAQG-YRQLMSGEDI IRALGISETVPSLG VQYAAPPLLGQALRRGQLDALLTFWHFSARLRGEGGVQTAFGLADLLGDLQLDAQLPVLG

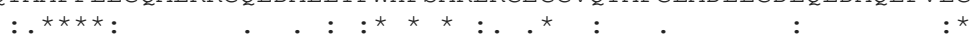

YLYEGHTVADRGEVVRGFARASAAAKDALANEPALWETVRPLMAAEDDATFATLKRDFLA YVFDEALLQRAPAAVAGLARAS SRAKRALEAGDAAWEPVRPLMAAEDEATYATLKRAFLE YVFDEAWANANKDLVARFIAVTRAAKEILATSDAEWDTIAPLTGAQDAATLHAYRERYRE YVFHEKWANENPDLAMNFLRASGEAKKLLARSDAEWQRLAPIVRAEGR-ELEMLRDRYRE YVLKGEYAATHPEIVKGLYKASRAAKDLLSENDEVWEELRDKMNAADDAEFIALRDGYRA YVFKQSWADQHETALQAFLQTAQTAKDTLCDSDAAWQQVMKLAETPDTAIQTQLKRRYCQ YLFPEPWAQANEALLQRFASALRQSKHELASEPAYWQA IRPLMRAEDEAVFAALRDSFVA

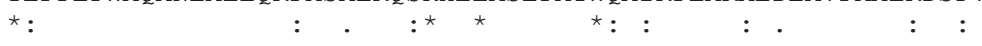

GIPRRPIAAERADGERIYAALDRLAGAQLLGVGKSLPPDLYLDASGNG ARADAERLYAVLARLGGERLVGAATTLPAGLYWDGGPNG GIPRRPIADEEADARVLYRVLAQLGGRDLVGTATELDPGTFYQAIPGD GIPNRPLAEEERDAAKLYEILAELGGEKLVGKARQMAPGTFWALKT-- 329 GIPSGKPID-EAAADRFLRLMAELGGEELVGKATSLPSGLFLHLE--- 323 GRVKQWGAAEQTAAGKIYQLLHRLSDNKLTGKTAQLQPGTFWSAH--- 321 GIPQPLDAARIADLQRLLVLTGS-------DPARLMPAALFQSAP--- 
Figure S4. Homology model of PqqT. This model was generated using SwissModel ${ }^{10}$ with ThiY (PDB code: 3IX1) as template, ${ }^{11}$ and visualized in PyMOL. ${ }^{12}$ (A) Overall structure. In the model, Cys192 (shown in sticks) is located on a loop that is present at the interface between the two domains, where the ligand binds in characterized PBPs. (B) The inset shows some of the putative residues lining the ligand-binding cavity of PqqT in sticks. As shown in Figure S3, many of these residues (especially K142, P170, W189, and F191) are highly conserved in putative PqqT homologues.

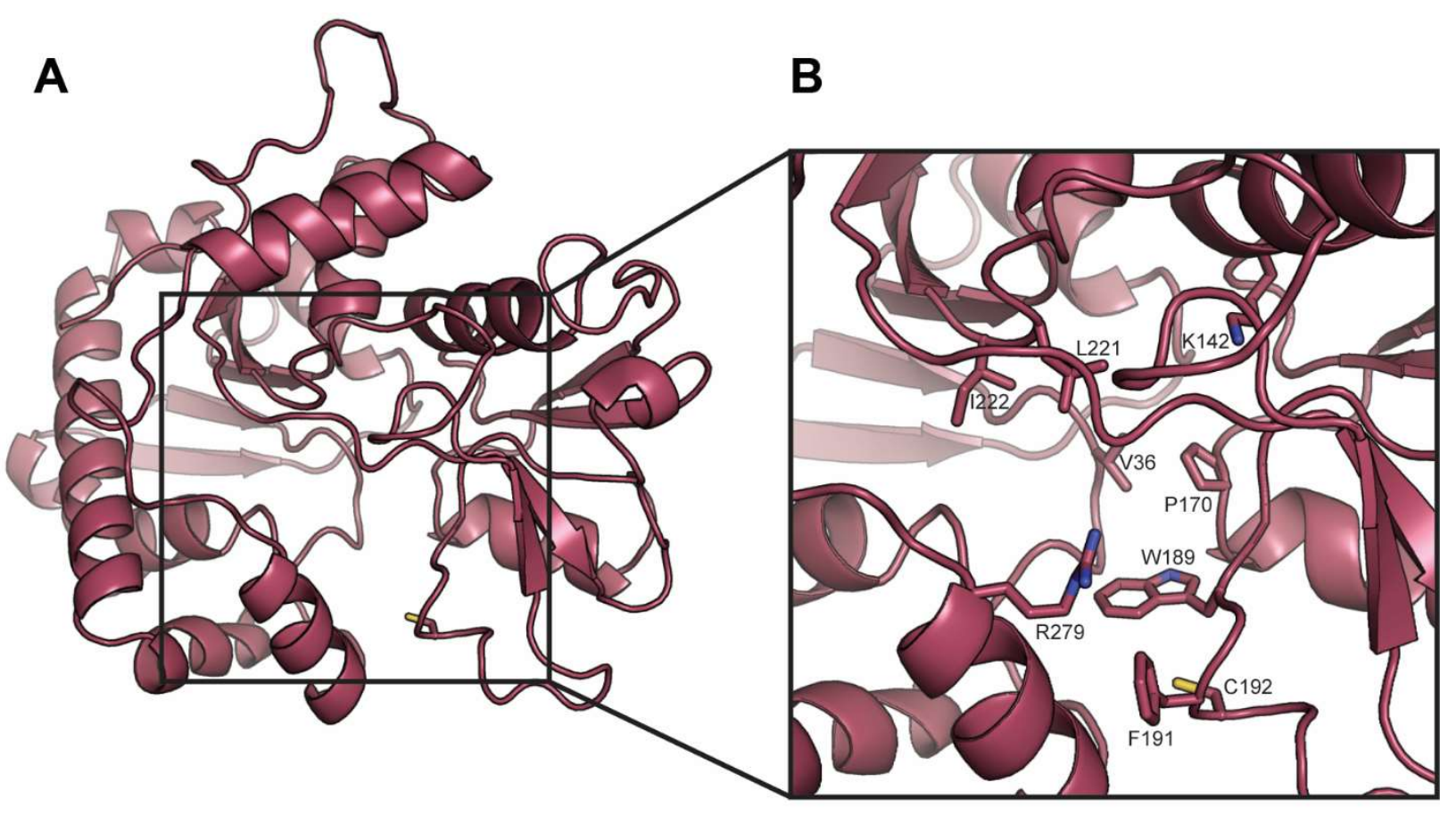


Figure S5. Expression and purification of full-length C-terminally His6-tagged PqqT (PqqT-His). (A) SDS-PAGE analysis of purification of PqqT-His from the E. coli periplasm. Lane 1: molecular weight marker. Lanes 2-3: pre- and post-induction samples. Lane 4: periplasmic extract. Lanes 56: Ni-NTA column flow-through and wash. Lane 7: purified protein $(9 \mu \mathrm{g})$. Lane 8: cytosolically expressed PqqT-His (see Figure S6). (B) Linear MALDI-TOF mass spectrum of PqqT-His. The $\mathrm{m} / \mathrm{z}=+1$ peak at $32770.658, \mathrm{~m} / \mathrm{z}=+2$ peak at 16382.441 , and $\mathrm{m} / \mathrm{z}=+3$ peak at 10921.109 correspond to the $\mathrm{N}$-terminal signal peptide being cleaved before Ala28 (expected mass: 32782.40 $\mathrm{Da}$; calculated masses 32764.882 and 32763.327 , respectively). The deviation from the expected mass is larger than the $100 \mathrm{ppm}$ uncertainty in the measurement and suggests a post-translational modification.

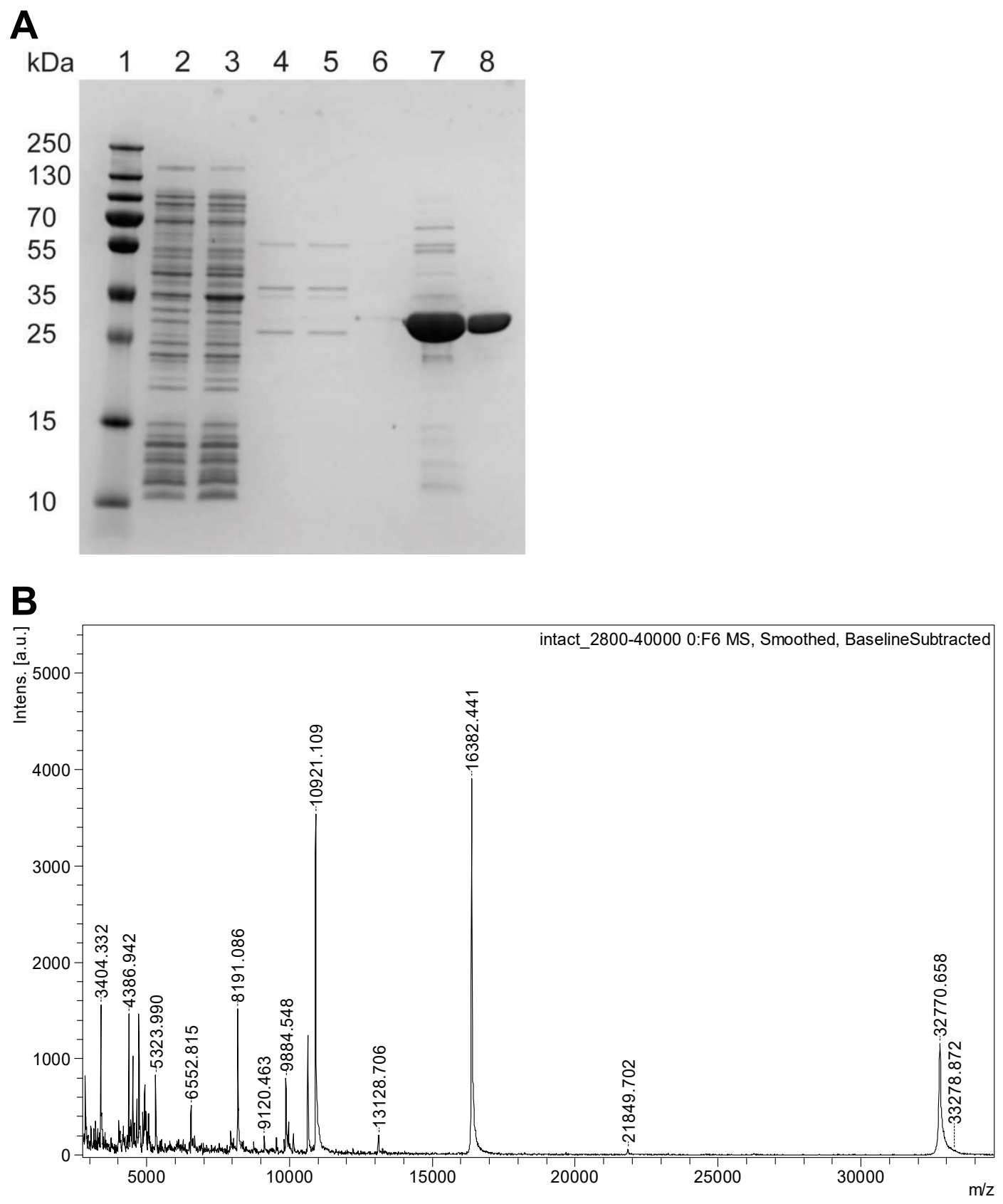


Figure S6. (A) SDS-PAGE analysis of purifications of C-terminally His ${ }_{6}$-tagged PqqT and PqqTC192A, expressed cytosolically (the constructs lack the N-terminal signal peptide). Lane 1: molecular weight marker. Lanes 2-6: purification of PqqT-His (pre-induction, post-induction, crude lysate following centrifugation, Ni-NTA column elution, after Superdex S75 chromatography). Lanes 7-11: purification of PqqT-C192A-His (pre-induction, post-induction, crude lysate following centrifugation, Ni-NTA column elution, after Superdex S75 chromatography). (B) Linear MALDI-TOF mass spectrum of PqqT-His, expressed cytosolically (top) compared to the exported protein (bottom, see also Figures S5 and S7). The $m / z=+2$ peak at 16393.392 and $m / z=+3$ peak at 10929.179 correspond to Ala28 as N-terminal residue (expected mass: $32782.40 \mathrm{Da}$; calculated masses 32786.78 and 32787.54 , respectively).

A

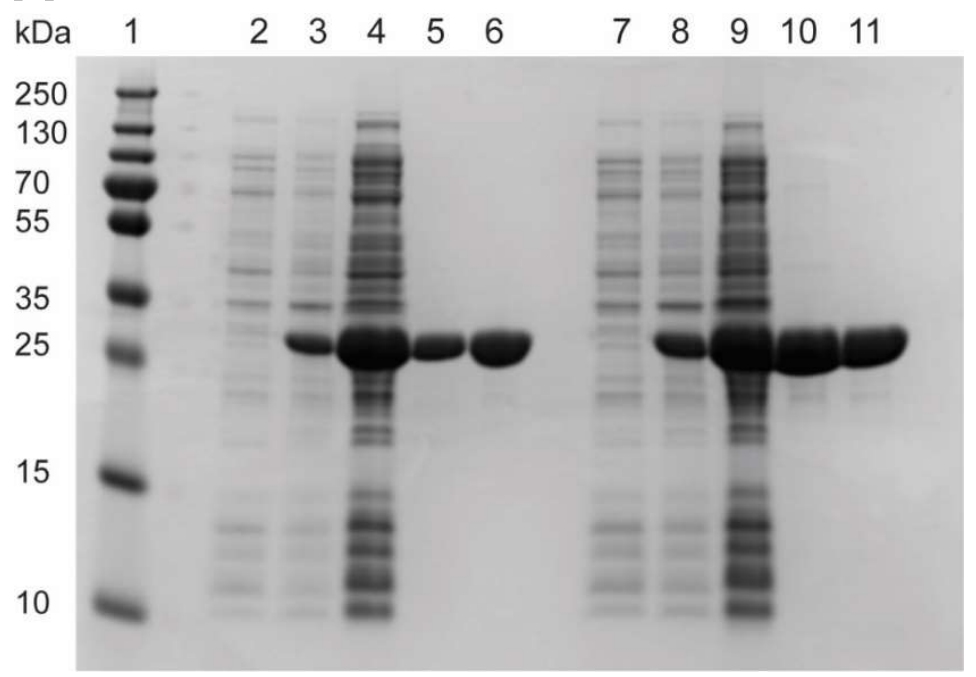

B

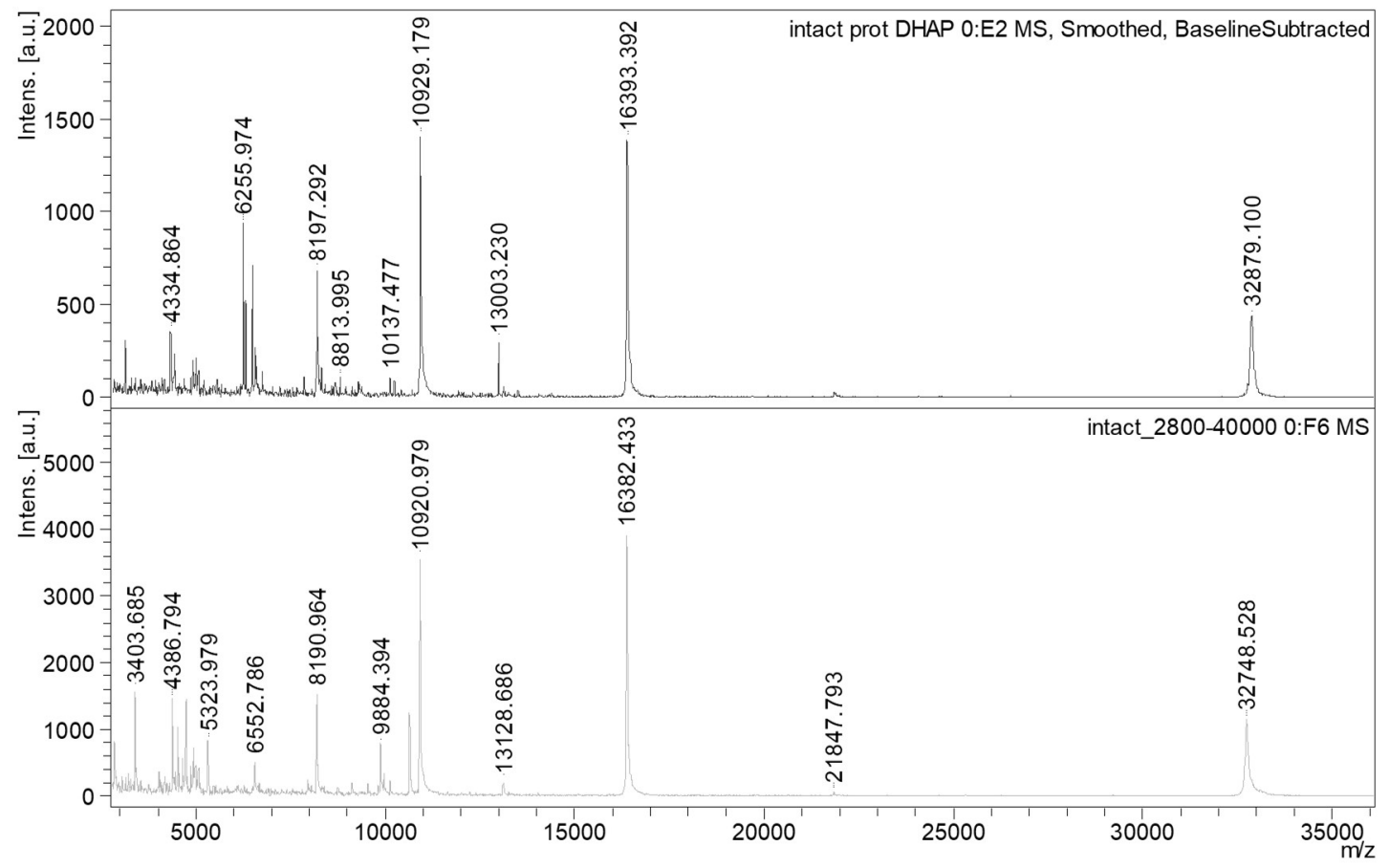


Figure S7. Linear MALDI-TOF mass spectra of tryptic digests of PqqT-His, purified from the periplasm (A) versus from the cytosol (B). Both samples were treated with iodoacetamide to carbamidomethylate free Cys residues prior to digestion. The spectra are highly similar, with the exception of a peak at 2066.955 in the periplasmic protein that is absent in the cytosolic protein, which instead features a peak at 2155.987. The latter corresponds to the peptide L $177_{17}$ ETGELDAALLYWQFCAR 194 with the Cys residue carbamidomethylated (+57.02 Da), and the former to the same peptide with Cys substituted by Ala (-31.97 Da), according to nano-LC/MS ${ }^{2}$ and Orbitrap analysis (see Figure S8).
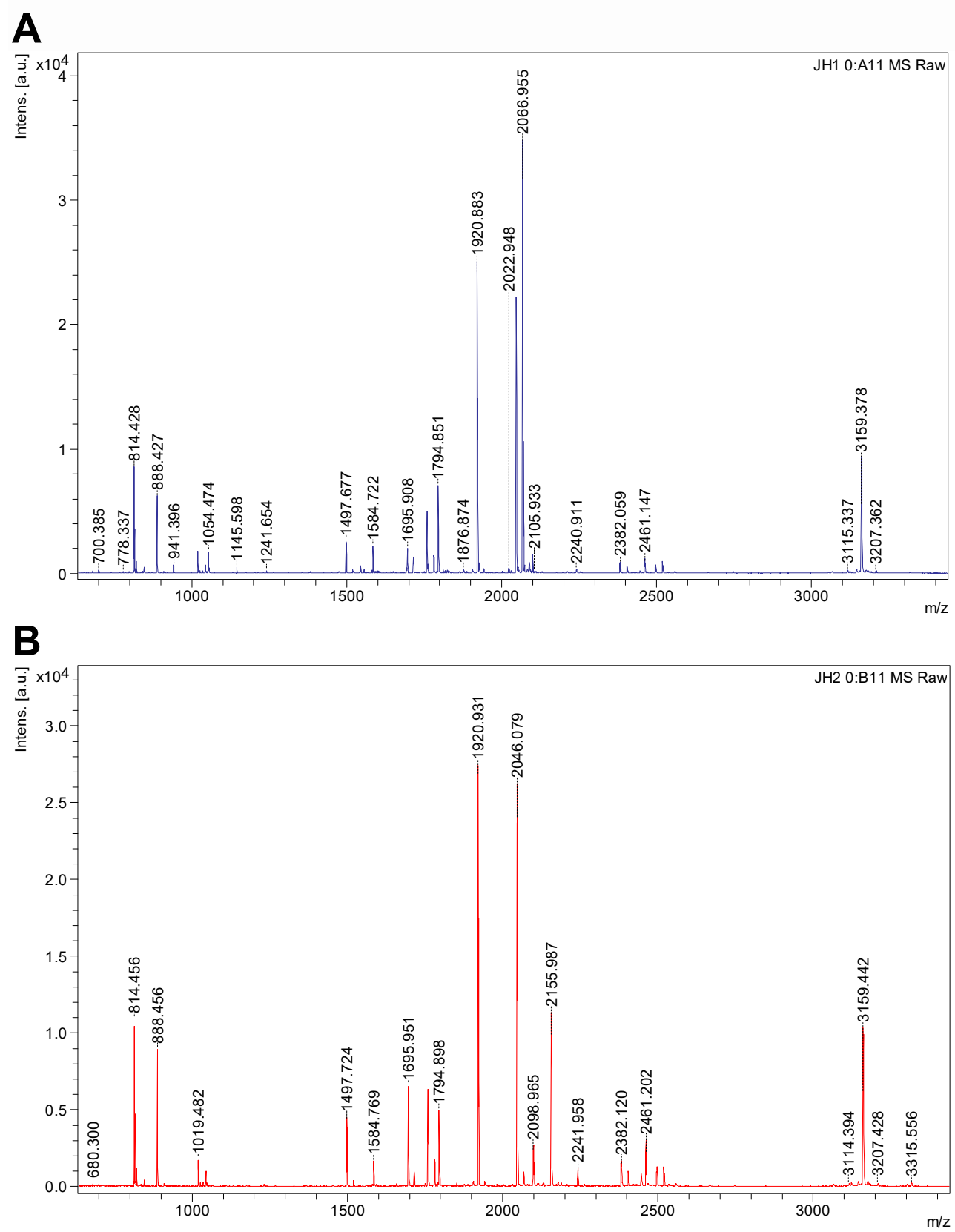
Figure S8. Portion of the HCD fragmentation mass spectrum showing the first five C-terminal fragments (y-ions) of the LYWQFAAR peptide, demonstrating desulfuration of C192 inside the E. coli cell. It is yet to be determined whether the same modification occurs within M. extorquens.

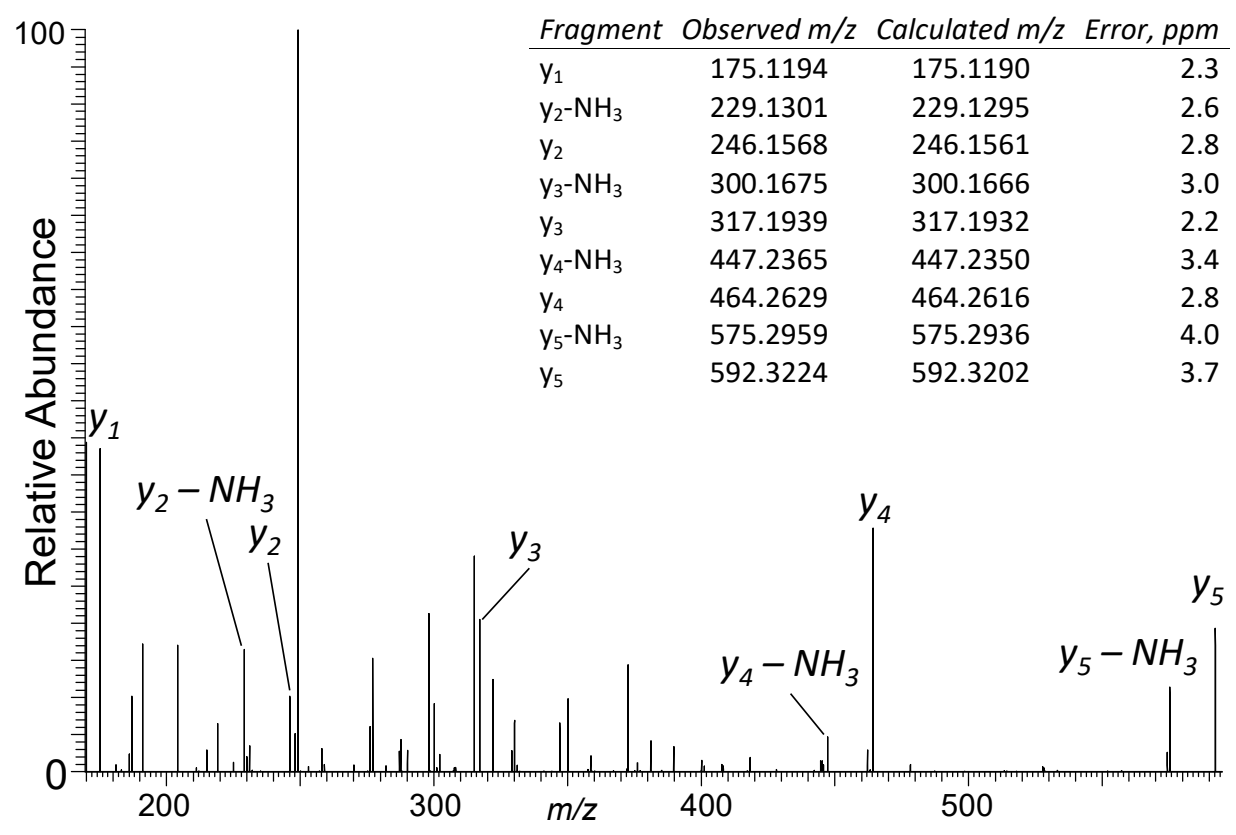


Figure S9. PqqT-His, purified from the E. coli periplasm, exhibits similar PQQ-binding properties as the cytosolically expressed and purified protein. (A) UV-visible titration of $12 \mu \mathrm{M}$ PQQ with 0-11 $\mu \mathrm{M}$ periplasmic PqqT-His. Although largely similar to the titrations with the wt- and C192A PqqTs purified from the cytosol (Figure 1A and Figure S13), there are slight differences in the proteins' isosbestic points (319 and $341 \mathrm{~nm}$ here, versus 330 and $359 \mathrm{~nm}$ for the cytosolic proteins). (B) Isothermal titration calorimetry study of PQQ binding to periplasmic PqqT-His. (Top) Representative ITC curves for titration of $30 \mu \mathrm{M}$ PqqT-His with $350 \mu \mathrm{M}$ PQQ. (Bottom) Binding isotherm derived from the data above. The fit (red line) is to a one-site model. The parameters from the fit (mean \pm standard deviation for two titrations): $n=1.15 \pm 0.01, K_{\mathrm{a}}=(9.00 \pm 3.45) \times$ $10^{6} \mathrm{M}^{-1}, \Delta H=39.2 \pm 0.8 \mathrm{~kJ} \mathrm{~mol}^{-1}$, and $\Delta S=264 \pm 1 \mathrm{~J} \mathrm{~mol}^{-1} \mathrm{~K}^{-1}$.

\section{A}

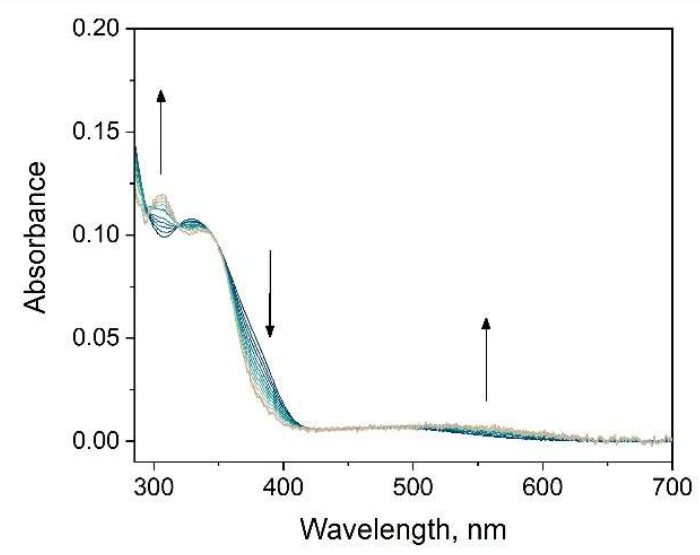

B

Time (min)

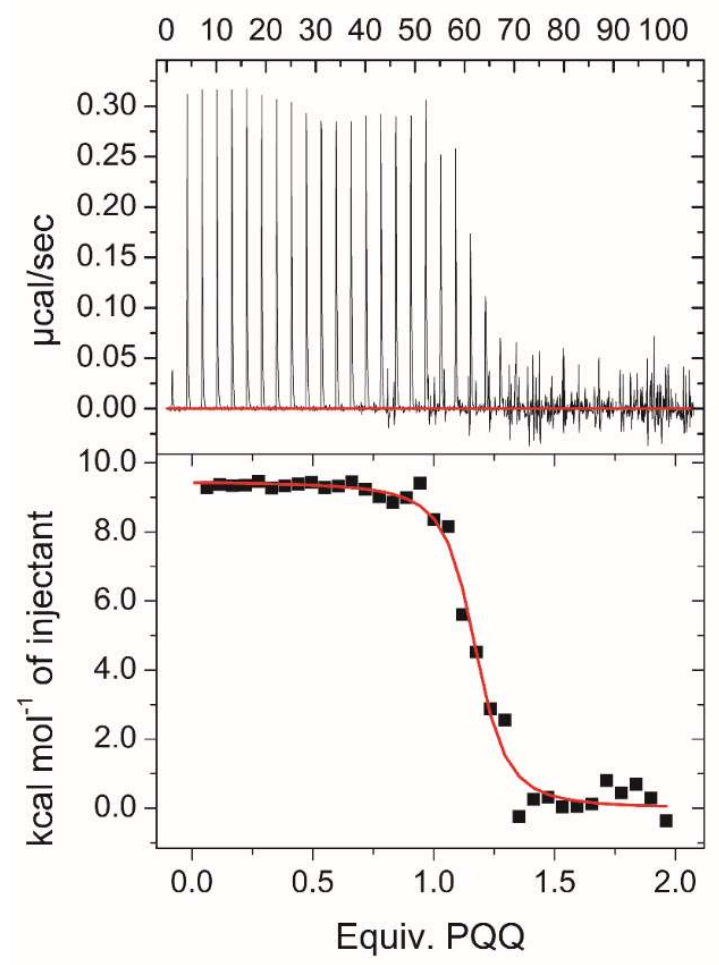


Figure S10. UV-visible absorption spectra of PQQ and PQQ-hydrate. These spectra were extrapolated from the spectra of a $10 \mu \mathrm{M}$ aqueous solution of PQQ at $25^{\circ} \mathrm{C}$ and $42{ }^{\circ} \mathrm{C}$, using the stated speciation of PQQ and PQQ-hydrate at those temperatures, as described. ${ }^{4}$

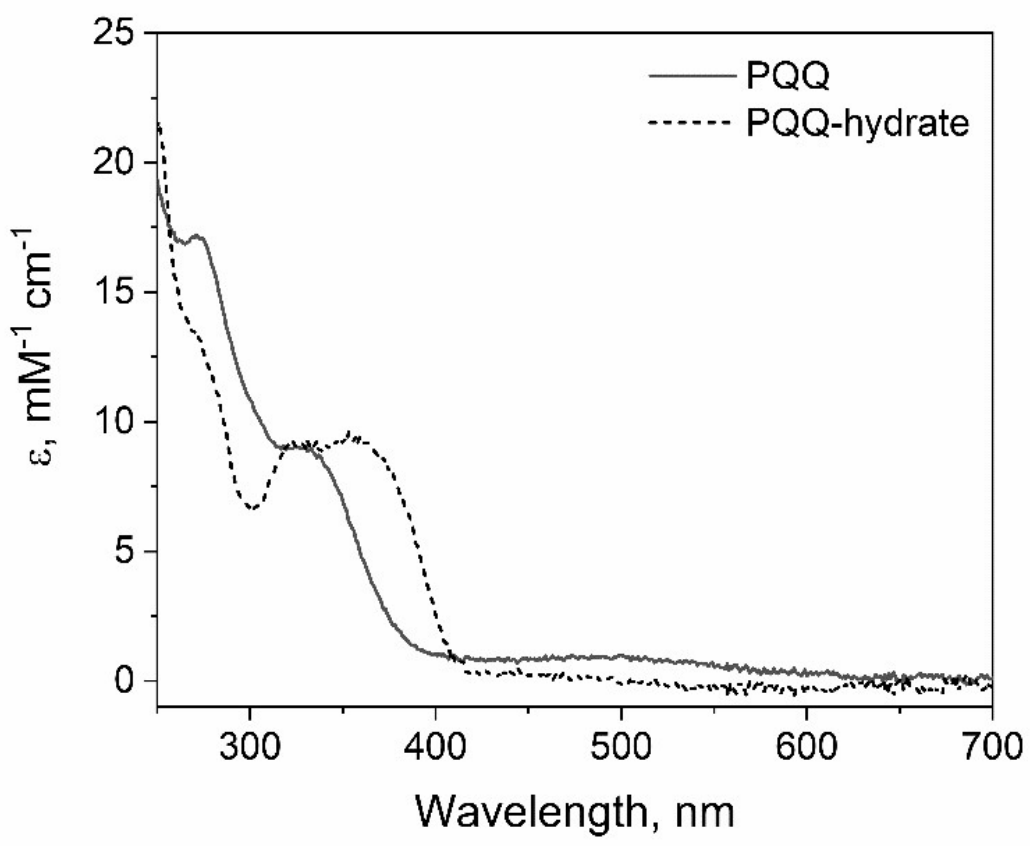


Figure S11. Titration of PQQ with PqqT monitored by UV-visible spectrophotometry. PQQ (13 $\mu \mathrm{M})$ was titrated anaerobically with $0-24 \mu \mathrm{M}$ PqqT in $1.5 \mu \mathrm{M}$ increments (dark blue to gray). Figure 1A was derived from this data after subtraction of the absorption contribution of the protein.

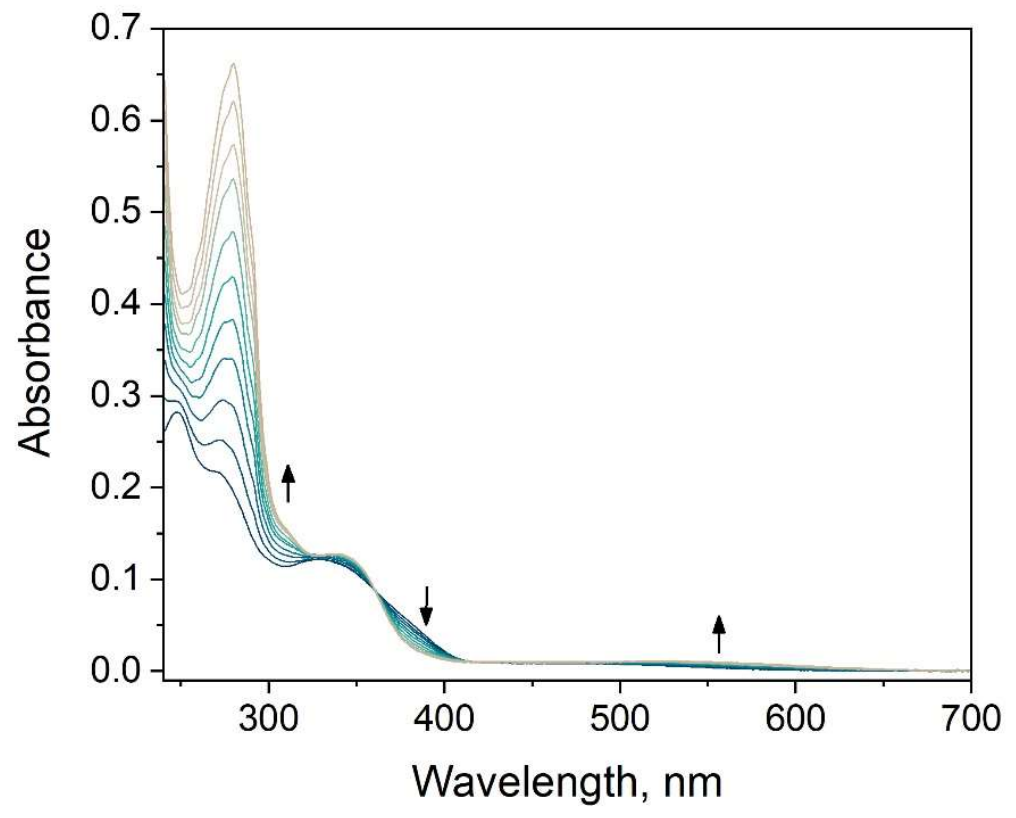


Figure S12. Comparison of the spectra of PQQ (see Figure S10) and PQQ bound to PqqT-C192A. (PQQ bound to the wild-type protein gives the same result). The spectrum of PQQ bound to PqqTC192A was determined by acquiring a spectrum of $20 \mu \mathrm{M}$ PqqT-C192A, adding $10 \mu \mathrm{M}$ PQQ and acquiring a spectrum, and subtracting the initial protein spectrum. The protein-bound spectrum shows differences versus the spectrum of the unhydrated form of PQQ, especially the presence of the $306 \mathrm{~nm}$ band in the presence of protein.

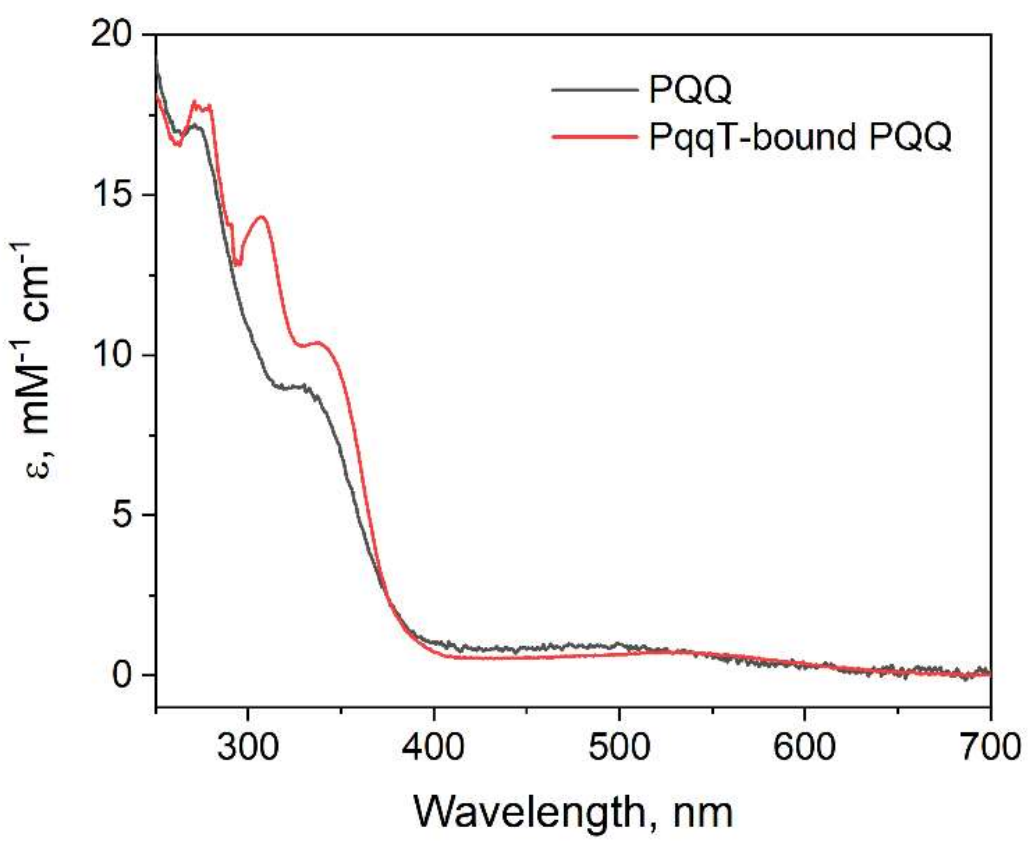


Figure S13. Binding of PQQ to PqqT-C192A, monitored by UV-visible absorption and spectrofluorometric titrations. (A) Titration of PQQ $(10 \mu \mathrm{M})$ with 0-20 $\mu \mathrm{M}$ PqqT-C192A (dark blue to gray), after subtraction of the absorption contribution of the protein from the overall spectra. (B) Absorbance changes at 306 and $384 \mathrm{~nm}$ allow for estimation of stoichiometry. (C) Fluorometric titration of PQQ $(10 \mu \mathrm{M})$ with $0-20 \mu \mathrm{M}$ PqqT-C192A in $1.0 \mu \mathrm{M}$ increments $(0-14$ $\mu \mathrm{L})$ and $2.0 \mu \mathrm{M}(14-20 \mu \mathrm{M})$ increments. (D) Fluorescence emission changes allow for estimation of stoichiometry. The results are nearly identical to those with the wt protein purified from the cytosol.

A

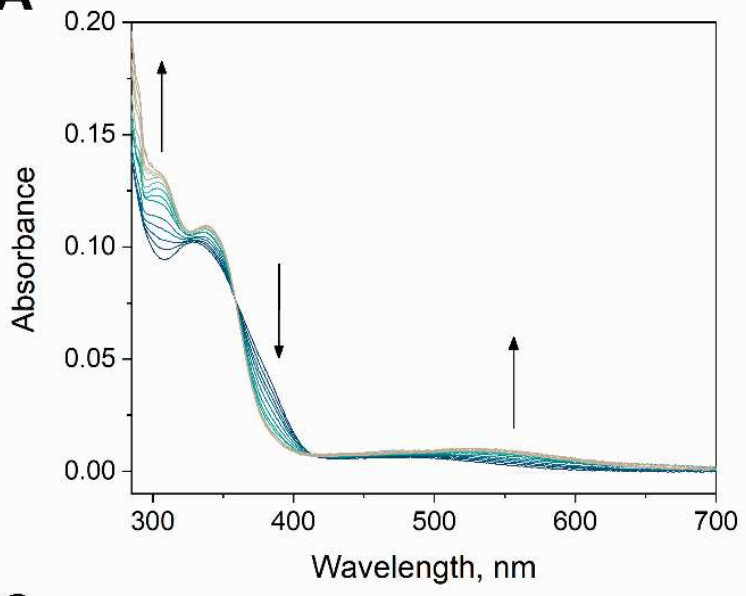

C

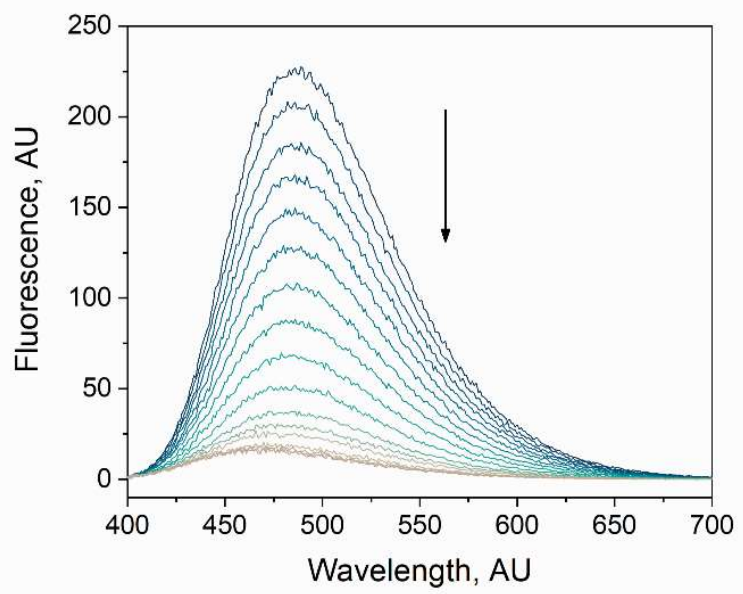

B

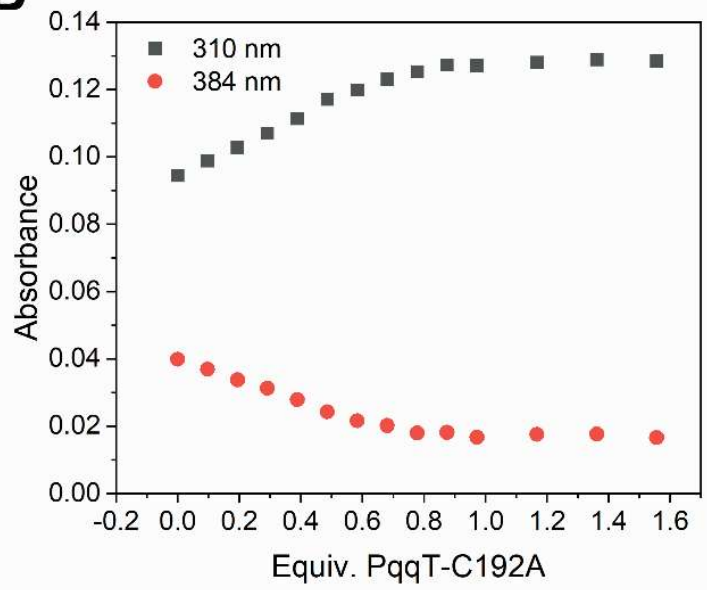

D

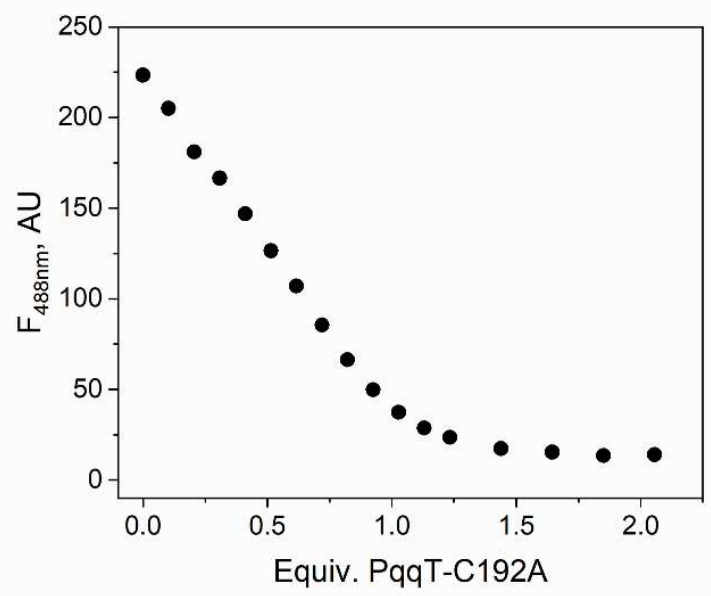


Figure S14. PQQ binding to PqqT-C192A, studied by isothermal titration calorimetry. (Top) Representative ITC curve for titration of $30 \mu \mathrm{M}$ PqqT with $350 \mu \mathrm{M}$ PQQ. (Bottom) Binding isotherm derived from the data above. The fit (red line) is to a one-site model. Experimental and derived parameters are shown in Table 1.

Time (min)

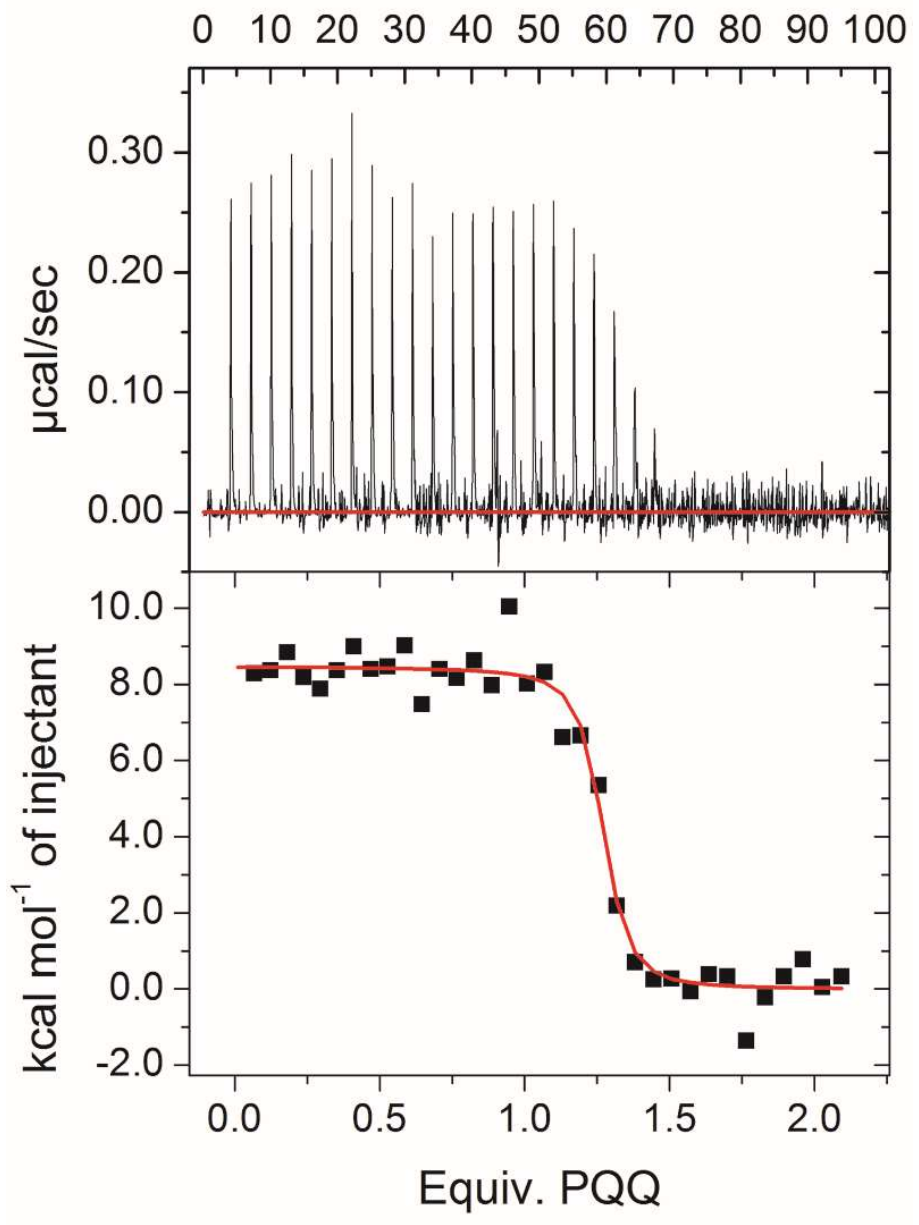


Figure S15. Titration of PqqT-C192A with folate, studied by isothermal titration calorimetry. (Top) Representative ITC curve for titration of $30 \mu \mathrm{M}$ PqqT with $350 \mu \mathrm{M}$ folate. The sharp feature at the beginning of the titration is an artifact from the first injection. (Bottom) Binding isotherm derived from the data above. The data suggest that folate does not bind to PqqT.

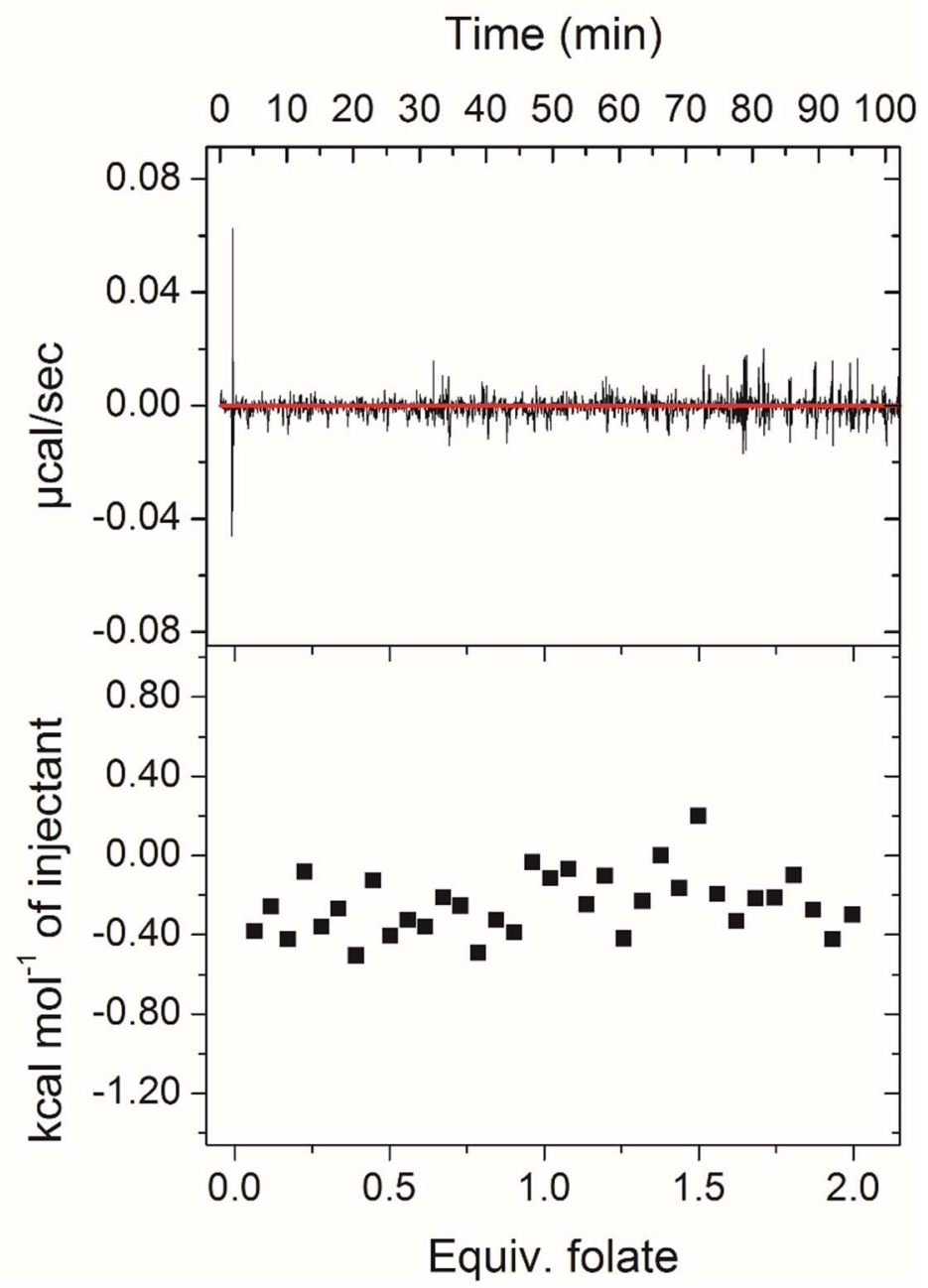




\section{SUPPLEMENTARY REFERENCES}

[1] Cotruvo, J. A., Jr., Featherston, E. R., Mattocks, J. A., Ho, J. V., and Laremore, T. N. (2018) Lanmodulin: A highly selective lanthanide-binding protein from a lanthanide-utilizing bacterium, J. Am. Chem. Soc. 140, 15056-15061.

[2] Gasteiger, E., Hoogland, C., Gattiker, A., Duvaud, S., Wilkins, M. R., Appel, R. D., and Bairoch, A. (2005) Protein Identification and Analysis Tools on the ExPASy Server, In The Proteomics Protocols Handbook (Walker, J. M., Ed.), pp 571-607, Humana Press, Totowa, NJ.

[3] Riddles, P. W., Blakeley, R. L., and Zerner, B. (1983) Reassessment of Ellman's reagent, Methods Enzymol. 91, 49-60.

[4] Dekker, R. H., Duine, J. A., Frank, J., Verweil, P. E. J., and Westerling, J. (1982) Covalent addition of $\mathrm{H}_{2} \mathrm{O}$, enzyme substrates and activators to pyrrolo-quinoline quinone, the coenzyme of quinoproteins, Eur. J. Biochem. 125, 69-73.

[5] M5518. (2015) The Merck Index Online, Royal Society of Chemistry.

[6] Caspi, R., Billington, R., Ferrer, L., Foerster, H., Fulcher, C. A., Keseler, I. M., Kothari, A., Krummenacker, M., Latendresse, M., Mueller, L. A., Ong, Q., Paley, S., Subhraveti, P., Weaver, D. S., and Karp, P. D. (2016) The MetaCyc database of metabolic pathways and enzymes and the BioCyc collection of pathway/genome databases, Nucl. Acids Res. 44, D471-D480.

[7] Shen, Y.-Q., Bonnot, F., Imsand, E. M., RoseFigura, J. M., Sjölander, K., and Klinman, J. P. (2012) Distribution and properties of the genes encoding the biosynthesis of the bacterial cofactor, pyrroloquinoline quinone, Biochemistry 51, 2265-2275.

[8] Bermingham, A., and Derrick, J. P. (2002) The folic acid biosynthesis pathway in bacteria: evaluation of potential for antibacterial drug discovery, BioEssays 24, 637-648.

[9] Madeira, F., Park, Y. M., Lee, J., Buso, N., Gur, T., Madhusoodanan, N., Basutkar, P., Tivey, A. R. N., Potter, S. C., Finn, R. D., and Lopez, R. (2019) The EMBL-EBI search and sequence analysis tools APIs in 2019, Nucl. Acids Res., doi: 10.1093/nar/gkz1268.

[10] Waterhouse, A., Bertoni, M., Bienert, S., Studer, G., Tauriello, G., Gumienny, R., Heer, F. T., de Beer, T. A. P., Rempfer, C., Bordoli, L., Lepore, R., and Schwede, T. (2018) SWISSMODEL: homology modelling of protein structures and complexes, Nucl. Acids Res. 46, W296-W303.

[11] Bale, S., Rajashankar, K. R., Perry, K., Begley, T. P., and Ealick, S. E. (2010) HMP binding protein ThiY and HMP-P synthase THI5 are structural homologues, Biochemistry 49, 8929-8936.

[12] Schrodinger, LLC. (2015) The PyMOL Molecular Graphics System, Version 1.8. 